\title{
Looking for the right TNM staging system for pancreatic neuroendocrine tumors
}

\author{
Nicola Fazio ${ }^{1}$, Francesca Spada ${ }^{1}$, Emilio Bertani ${ }^{2}$ \\ ${ }^{1}$ Division of Gastrointestinal Medical Oncology and Neuroendocrine Tumors, European Institute of Oncology, IEO, IRCCS, Milan, Italy; ${ }^{2}$ Division \\ of Digestive Surgery, European Institute of Oncology, IEO, IRCCS, Milan, Italy \\ Correspondence to: Nicola Fazio, MD, PhD. Division of Gastrointestinal Medical Oncology and Neuroendocrine Tumors, European Institute of \\ Oncology, IEO, IRCCS, Via Ripamonti 435, 20141 Milan, Italy. Email: nicola.fazio@ieo.it. \\ Comment on: Zhang XF, Xue F, Wu Z, et al. Development and Validation of a Modified Eighth AJCC Staging System for Primary Pancreatic \\ Neuroendocrine Tumors. Ann Surg 2020. [Epub ahead of print]. doi: 10.1097/SLA.0000000000004039.
}

Submitted Jan 02, 2021. Accepted for publication Jan 20, 2021.

doi: 10.21037/hbsn-2021-1

View this article at: http://dx.doi.org/10.21037/hbsn-2021-1

Pancreatic neuroendocrine tumors (panNETs) represent a rare subgroup of neuroendocrine neoplasms (NENs) which showed an impressive increase of incidence over the last decade (1). As over the same period particularly low stage and low grade NETs had the highest increase it is plausible that small (e.g., $</=2 \mathrm{~cm}$ ) panNETs incidentally detected may have had a major role thanks to the progress of imaging.

Pancreatic NENs are classified according to the grade of differentiation and proliferation index, into four categories including panNETs G1 [well differentiated (WD) with $<3 \% \mathrm{Ki}-67$ ], panNETs G2 (WD with 3-20\% Ki-67), panNETs G3 (WD with $>20 \% \mathrm{Ki}-67$ ) and pancreatic neuroendocrine carcinomas (panNECs) [poorly differentiated (PD) with $>20 \% \mathrm{Ki}-67]$ in accordance with the 2017 WHO classification (2).

For localized and locally advanced panNETs curative treatment typically consist of radical surgery of the primary tumors +/- regional nodes. Over the last 15 years several TNM staging systems were developed, including ENETS TNM 2006 and 2007, and UICC/AJCC $7^{\text {th }}$ and $8^{\text {th }}$ editions) (3-6).

A particular criticism of AJCC TNM 7th ed. was that the stage III, defined as tumoral involvement of the celiac axis or the superior mesenteric artery (unresectable tumor) without distant metastasis, was very limited ( $<5 \%$ of cases) (7), unlike pancreatic adenocarcinoma (PDAC).

ENETS TNM staging system for panNENs was reported as superior to the UICC/AJCC/WHO 2010 TNM $7^{\text {th }}$ edition by Guido Rindi and co-authors (7). The former system "perfectly allocated patients $(n=1,072)$ in four risk groups" that showed significantly differences as for survival and were equally populated, whereas the latter distinguished three groups differently populated, with most patients in stage I and a clear overlapping for stage II and III. ENETS staging system resulted more accurate than the UICC/AJCC one. However, some shortcomings of ENETS TNM were reported, including a similar prognosis between stage I and IIA and a better survival for stage IIIB than IIIA. On this basis a "modified ENETS" staging system for panNETs was proposed (8).

In 2017 AJCC updated its TNM staging system by publishing its $8^{\text {th }}$ edition, that reported two separated staging systems for panNENs, one for WD panNETs (G1, G2, G3), on the basis of the ENETS 2006 TNM, and the other for PD panNECs (G3), that is the same than the PDAC staging system. For panNETs, the main changes included: (I) a size upper limit of $4 \mathrm{~cm}$ for the T2; (II) a specific definition of the T3, changing from a general "beyond the pancreas" to $>4 \mathrm{~cm}$ or invading only duodenum or common bile duct; (III) all the other adjacent structures were in the T4 together with celiac axis or the mesenteric superior artery infiltration; (IV) in addition to the T4 any-N M0, also any-T N1 M0 were classified as stage III. A main difference between PDAC/panNECs and panNETs $8^{\text {th }}$ edition TNM staging system was the $\mathrm{N}$ category, as it was based on the number of lymph node metastases (LNM) for PDAC/panNECs, defining N0 (no LNM), N1 (1-3 LNM) and N2 (>3 LNM), whereas it was based on 
presence/absence of LNM for panNETs, defining only N0 (no LNM) versus N1 (>/=1 LNM).

Although the AJCC TNM $8^{\text {th }}$ edition was validated with large-scale studies (9) other Authors addressed the debatable nodal binary stratification by suggesting that a lymphadenectomy of at least 8 lymph-nodes is necessary to stage patients with panNETs and a trinary rather than binary stratification would be indicated. On this background Dr. Zhang and co-authors proposed a "modified" (m)TNM staging system for panNETs (10). Their study was based on a large series of patients with panNETs resected with curative intent: 825 patients from the multi-institutional database (period 2000-2016) of the US neuroendocrine tumors study group (US-NETSG) and 3,303 patients from the SEER database (period 1975-2016). The authors concluded that "the eighth TNM staging system failed to stratify patients with stage I versus IIA, stage IIB versus IIIA, and overall stage I versus II relative to long-term OS in both database". By contrast a modified TNM staging system using N0 (no LNM), N1 (1-3 LNM), and N2 (>3 LNM) categories "was better at stratifying patients relative to long-term OS". In fact, stage IA-B and IIA-B is included only in the ENETS staging system, whereas the AJCC TNM $8^{\text {th }}$ edition reported stage I (T1 N0 M0), stage II (T2-3 N0 M0) and stage III (T4 N0 M0, any-T N1 M0). Therefore, the focus of the study regarded the stage III.

Twenty-six percent and $12 \%$ of patients had $1-3$ and $>3$ LNM in the SEER database, respectively and $18 \%$ and $8 \%$ in the US-NETSG database, respectively. Unfortunately, it is not possible to know how many T1 were associated with $\mathrm{N}+$. This would be important to know as surveillance is often proposed to non-functioning $\mathrm{T} 1(>/=2 \mathrm{~cm})$ panNET patients, as reported by the authors in the discussion. While the authors reported a "very good prognosis after surgical resection" for stage IA panNETs, with around 100\% 5-year survival rate, no specific survival information was reported for T1 N1 M0 (stage IIB) and T1 N2 M0 (stage III) of the modified $8^{\text {th }}$ AJCC TNM.

With their mTNM, Zhang and co-authors showed that T3 N1 (1-3 LNM) M0 panNET patients had a better survival than T4 N0 M0. However, it is unknown if T1 N1 M0 could have a better survival than T3 N0 M0 or if there is a significant difference between T3 N1 M0 and T4 N0 M0.

Another open question regards the role of the tumor grade. While it seems that "G3 neuroendocrine carcinomas" were excluded from the Zhang's study, it is not clear if and how many "NET G3" were included. They could have a prognostic major role regardless tumor stage.
Furthermore, relapse free survival (RFS) and the related medical treatment could have impacted OS, so this unknown information would be interesting to know.

In conclusion, we think that Dr. Zhang's study raised an important issue for panNET staging, that should be considered for future studies together with other poor prognostic factors of radically resected panNETs. Unfortunately, in clinical practice there is no current evidence to use this information for adjuvant therapeutic choice.

\section{Acknowledgments}

Funding: None.

\section{Footnote}

Provenance and Peer Review: This article was commissioned by the editorial office of Hepatobiliary Surgery and Nutrition. The article did not undergo external peer review.

Conflicts of Interest: All authors have completed the ICMJE uniform disclosure form (available at https://hbsn. amegroups.com/article/view/10.21037/hbsn-2021-1/coif). The authors have no conflicts of interest to declare.

Ethical Statement: The authors are accountable for all aspects of the work in ensuring that questions related to the accuracy or integrity of any part of the work are appropriately investigated and resolved.

Open Access Statement: This is an Open Access article distributed in accordance with the Creative Commons Attribution-NonCommercial-NoDerivs 4.0 International License (CC BY-NC-ND 4.0), which permits the noncommercial replication and distribution of the article with the strict proviso that no changes or edits are made and the original work is properly cited (including links to both the formal publication through the relevant DOI and the license). See: https://creativecommons.org/licenses/by-nc-nd/4.0/.

\section{References}

1. Dasari A, Shen C, Halperin D, et al. Trends in the Incidence, Prevalence, and Survival Outcomes in Patients With Neuroendocrine Tumors in the United States. JAMA Oncol 2017;3:1335-42.

2. Nagtegaal ID, Odze RD, Klimstra D, et al. The 2019 
WHO classification of tumours of the digestive system. Histopathology 2020;76:182-8.

3. Rindi G, Kloppel G, Alhman H, et al. TNM staging of foregut (neuro)endocrine tumors: a consensus proposal including a grading system. Virchows Arch 2006;449:395-401.

4. Rindi G, Kloppel G, Couvelard A, et al. TNM staging of midgut and hindgut (neuro) endocrine tumors: a consensus proposal including a grading system. Virchows Arch 2007;451:757-62.

5. Edge SB, Compton CC. The American Joint Committee on Cancer: the 7th edition of the AJCC cancer staging manual and the future of TNM. Ann Surg Oncol 2010;17:1471-4.

6. Amin MB, Greene FL, Edge SB, et al. The Eighth Edition AJCC Cancer Staging Manual: Continuing to build a bridge from a population-based to a more "personalized" approach to cancer staging. CA Cancer J Clin 2017;67:93-9.

Cite this article as: Fazio N, Spada F, Bertani E. Looking for the right TNM staging system for pancreatic neuroendocrine tumors. HepatoBiliary Surg Nutr 2021;10(3):382-384. doi: 10.21037/hbsn-2021-1
7. Rindi G, Falconi M, Klersy C, et al. TNM staging of neoplasms of the endocrine pancreas: results from a large international cohort study. J Natl Cancer Inst 2012;104:764-77.

8. Luo G, Javed A, Strosberg JR, et al. Modified Staging Classification for Pancreatic Neuroendocrine Tumors on the Basis of the American Joint Committee on Cancer and European Neuroendocrine Tumor Society Systems. J Clin Oncol 2017;35:274-80.

9. You Y, Jang JY, Kim SC, et al. Validation of the 8th AJCC Cancer Staging System for Pancreas Neuroendocrine Tumors Using Korean Nationwide Surgery Database. Cancer Res Treat 2019;51:1639-52.

10. Zhang XF, Xue F, Wu Z, et al. Development and Validation of a Modified Eighth AJCC Staging System for Primary Pancreatic Neuroendocrine Tumors. Ann Surg 2020. [Epub ahead of print]. doi: 10.1097/ SLA.0000000000004039. 